\title{
Modification of the Antidiuretic Effect of Vasopressin by Acid and Alkaline Loads *
}

\author{
T. D. Ullmann, $\dagger$ W. J. Czaczkes, and J. Menczel with the technical \\ ASSISTANCE OF Y. WERECHSON \\ (From the Laboratory of Clinical Research and the Medical Department " $A$," Rothschild \\ Hadassah University Hospital and The Hebrew University-Hadassah \\ Medical School, Jerusalem, Israel)
}

Impaired urinary concentrating ability has been described in various clinical and experimental conditions. In many of these conditions the urine is alkaline, and other abnormalities in its ionic composition have been described or may be expected from the circumstances (1-8). It appeared possible, therefore, that the antidiuretic effect of endogenous vasopressin might be influenced by the $\mathrm{pH}$ and by the ionic composition of the body fluids and of the tubular urine.

This paper deals with the effect of vasopressin in dogs infused with hypotonic solutions of sodium chloride, ammonium chloride, and sodium bicarbonate and shows that the antidiuretic action of small doses of vasopressin is modified by the administration of acid and alkaline solutions.

\section{Methods}

The experiments were carried out on untrained fasting female dogs weighing 11.8 to $27 \mathrm{~kg}$. The dogs were kept on a diet of Purina and powdered milk. They were anesthetized by intraperitoneal injection of $30 \mathrm{mg}$ per $\mathrm{kg}$ sodium thiopentone (intraval sodium), the effect of which lasted for about 30 minutes. During this time polyethylene tubes were inserted into veins and artery, a catheter was inserted into the bladder, and an infusion of ethanol was started at a rate of 0.1 to $0.15 \mathrm{ml}$ per minute. This infusion, which was maintained throughout the experiments, kept the animals under light anesthesia and served also to abolish the release of endogenous antidiuretic material $(9,10)$.

* Submitted for publication February 27, 1961; accepted January 14, 1965.

Aided by grants from the Joint Research Fund, Hebrew University-Hadassah Medical School, and from the U. S. Department of Agriculture (Fg-Is-194).

Presented in part before the First International Congress of Nephrology, Geneva and Evian, September 1960.

$\dagger$ Address requests for reprints to Dr. T. D. Ullmann, Laboratory of Clinical Research, Hadassah University Hospital, Jerusalem, Israel.
Hypotonic solutions of sodium chloride, ammonium chloride, and sodium bicarbonate were infused at a rate of $7.4 \mathrm{ml}$ per minute, with a Bowman constant infusing pump. The solutions were made up to contain $100 \mathrm{mOsm}$ per $\mathrm{L}$ of the electrolyte solution and $100 \mathrm{mOsm}$ per $\mathrm{L}$ of glucose. Thus, the amount of electrolytes infused was $740 \mu$ Osm per minute. Inulin was added to the infusion for the determination of glomerular filtration rate.

During each experiment only one type of electrolyte solution was used. The infusion was given until a constant urinary flow with low osmolality was obtained, which usually took 3 to 4 hours. The solution was then changed for an identical one, containing vasopressin ${ }^{1}$ in varying amounts. In the experiments with sodium bicarbonate the vasopressin was given in a glucose solution into a separate vein, in order to avoid prolonged contact of the vasopressin with the alkaline solution. Urine samples were collected every 10 to 20 minutes for determination of $\mathrm{pH}$ and total osmolality. Blood samples were taken every 20 minutes for the determination of total osmolality. In part of the experiments the blood $\mathrm{pH}$ was determined at various times during the infusion. The vasopressin infusions were continued to allow antidiuretic effect to become evident and constant, and after an interval, during which the corresponding solution without vasopressin was infused, a higher concentration of vasopressin was given. In a few instances, this was done without a vasopressin-free interval. The range of vasopressin dosage in these experiments was 0.48 to $12.6,0.27$ to 6.5 , and 0.28 to $10.0 \mu \mathrm{U}$ per $\mathrm{kg}$ per minute for the experiments with sodium chloride, ammonium chloride, and sodium bicarbonate, respectively.

As it was observed that the dogs possessed individual degrees of sensitivity towards vasopressin, additional experiments were carried out on six dogs, in which the three types of salt solutions were given to the same dog in separate experiments. There was an interval of at least 2 weeks between subsequent experiments. In this set of experiments only two doses of vasopressin were used ( 0.48 and $0.72 \mu \mathrm{U}$ per $\mathrm{kg}$ per minute).

Osmolality was determined cryoscopically with a thermistor-type apparatus (Fiske) ; the $\mathrm{pH}$ in blood and urine was determined with a Beckman $\mathrm{pH}$ meter. Inulin was

\footnotetext{
1 Pitressin, lot no. L749B, Parke, Davis \& Co., Detroit, Mich.
} 
measured by the method of Roe, Epstein, and Goldstein (11).

\section{Results}

Representative experiments with each type of solution and with increasing doses of vasopressin are illustrated in Figures 1 to 4.

Figure 1 shows the results of administering $2.5,7.6$, and $12.6 \mu \mathrm{U}$ per $\mathrm{kg}$ per minute of Pitressin to $\operatorname{dog} \mathrm{J}$ during the infusion of hypotonic sodium chloride solution. A definite antidiuretic effect, i.e., a fall in urinary flow, a rise in urinary osmolality, and a corresponding fall in free water clearance became manifest during the administration of the smallest amount of vasopressin used. The effect became more pronounced during the infusion of the intermediate dose, whereas the largest dose had a similar, but somewhat lesser effect.

In the experiments with ammonium chloride (Figure 2, dog $\mathrm{K}$ ) the vasopressin dosage was gradually raised from 0.37 to $0.75,1.5$, and finally $3.0 \mu \mathrm{U}$ per $\mathrm{kg}$ per minute. In these experiments the small initial amount of vasopressin had an anti- diuretic effect, which equaled that obtained in the sodium chloride experiments with a much larger initial dosage. The administration of 1.5 and 3.0 $\mu \mathrm{U}$ per kg per minute had a more pronounced antidiuretic effect than doses 4 to 5 times as large given in the sodium chloride experiments.

Figure 3 (dog L) illustrates one of the experiments with sodium bicarbonate solution, with a vasopressin range of $0.28,0.55,5.5$, and $10.0 \mu \mathrm{U}$ per $\mathrm{kg}$ per minute. Only during the administration of the two larger amounts of vasopressin could a definite antidiuretic effect be observed, which was still less, however, than that seen with similar or even smaller amounts in the sodium chloride and ammonium chloride experiments. The two initial doses of vasopressin resulted in a rise of urinary flow, whereas the urinary osmolality remained unchanged.

In Figure 4, the period to period changes in three different experiments on the same dog (dog $\mathrm{S})$, and with the same amount of vasopressin (0.48 $\mu \mathrm{U}$ per $\mathrm{kg}$ per minute), are compared.

\section{$\mathrm{NaCl}$-Solution \\ DOG J. $12.7 \mathrm{~kg}$}

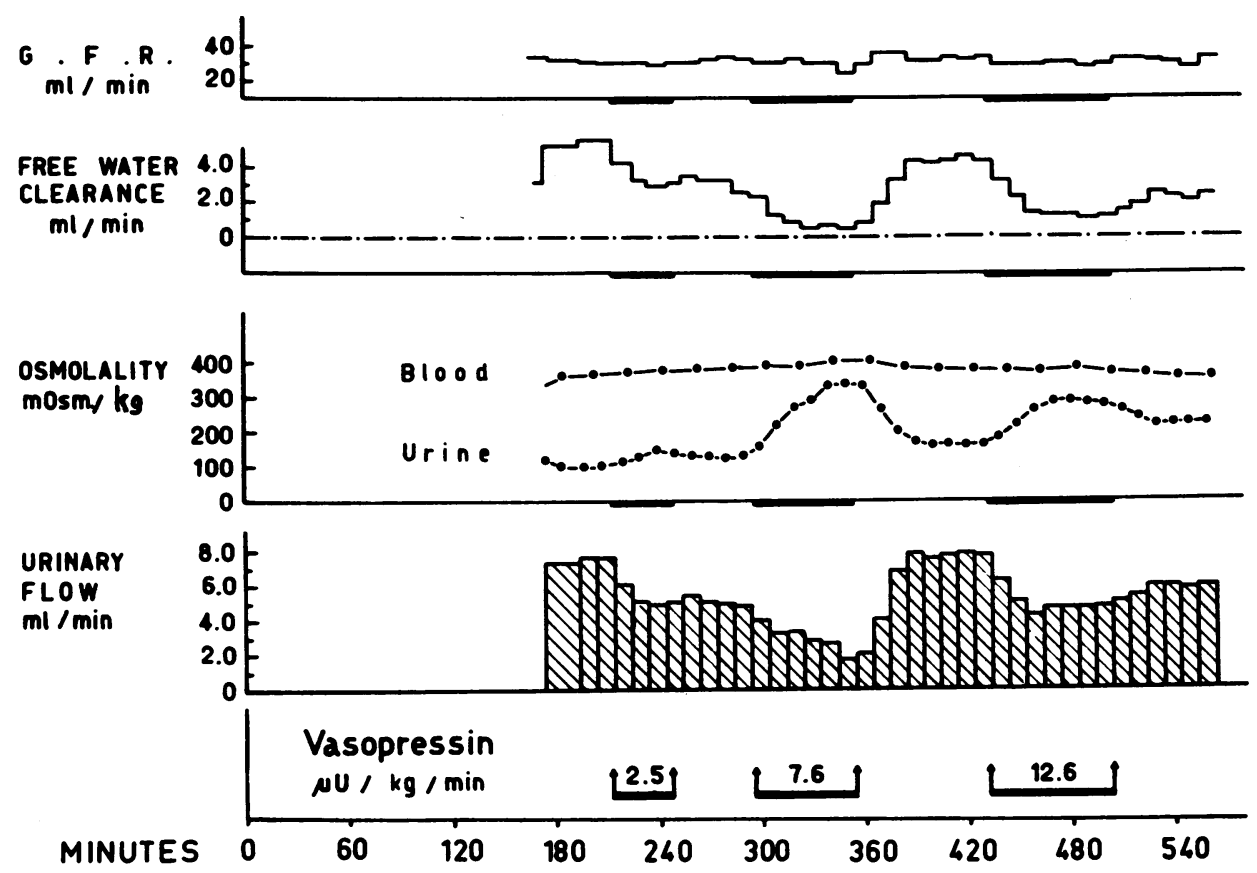

Fig. 1. Changes in URinary volume, osmolality, and Free water clearance caused IN DOG J BY THE ADMINISTRATION OF VASOPRESSIN DURING THE INFUSION OF HYPOTONIC SODIUM CHLORIDE SOLUTION. GFR = glomerular filtration rate. 


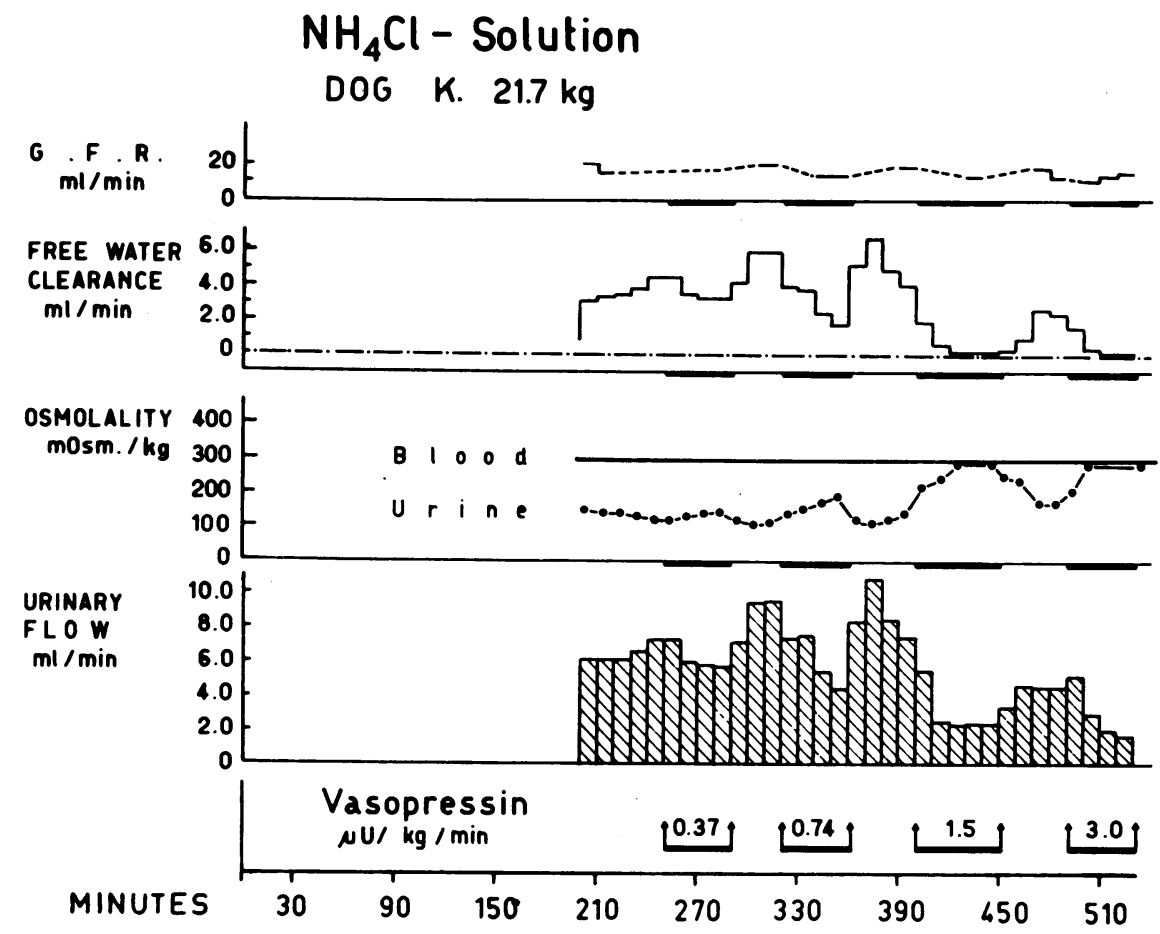

Fig. 2. Changes in URinary volume, osmolality, and free water Clearance CAUSED IN DOG $\mathrm{K}$ BY THE ADMINISTRATION OF VASOPRESSIN DURING THE INFUSION OF HYPOTONIC AMMONIUM CHLORIDE SOLUTION.

With $\mathrm{NH}_{4} \mathrm{Cl}$ and $\mathrm{NaCl}$ pronounced antidiuresis was observed; with $\mathrm{NaHCO}_{3}$ only minor changes were noted.

Table I compares the effect of vasopressin on urinary flow, urinary osmolality, and free water clearance during the infusion of the three salt solutions in identical dogs. In most of the animals the effect of vasopressin on urine volume and osmolality was largest with ammonium chloride and smallest or absent with sodium bicarbonate, whereas with sodium chloride intermediate effects were observed. In dog U, an antidiuretic effect could only be seen during the infusion of $\mathrm{NH}_{4} \mathrm{Cl}$.

In Tables II to IV the results of all experiments are summarized, with data concerning glomerular filtration rate, osmolar excretion, and changes in urinary $\mathrm{pH}$ included.

A. Antidiuretic effect. In all $\mathrm{NH}_{4} \mathrm{Cl}$ experiments and in 15 of 16 experiments with $\mathrm{NaCl}$ an antidiuretic effect occurred, whereas with $\mathrm{Na}$ $\mathrm{HCO}_{3}$ a definite antidiuresis could be observed only in 9 of 15 experiments.

B. Glomerular filtration rate. In most instances, the GFR remained constant or showed only minor alterations throughout the experiments. Such changes as occurred did not show any definite pattern, and rises as well as falls in GFR were observed, which did not accompany changes in the same direction of the urinary flow. In some of the experiments on identical animals, GFR seemed to be somewhat lower during the infusion of $\mathrm{NH}_{4} \mathrm{Cl}$ than during the infusion of the other solutions.

C. Solute excretion. Although the salt solutions were infused at a constant rate $(740 \mu \mathrm{Osm}$ per minute) throughout the whole duration of the experiments, the solute output showed considerable fluctuations, especially after the infusion of vasopressin. Rises were somewhat more frequently observed than falls, but no correlation became manifest between these changes and either the type of salt solution or the vasopressin dosage employed. During the control periods, the urines were markedly hypotonic even with the highest solute excretion rates.

D. Changes in $p H$. The urinary $\mathrm{pH}$ was 6.0 to 7.0, 5.6 to 7.1 , and 7.3 to 8.4 , respectively, during 


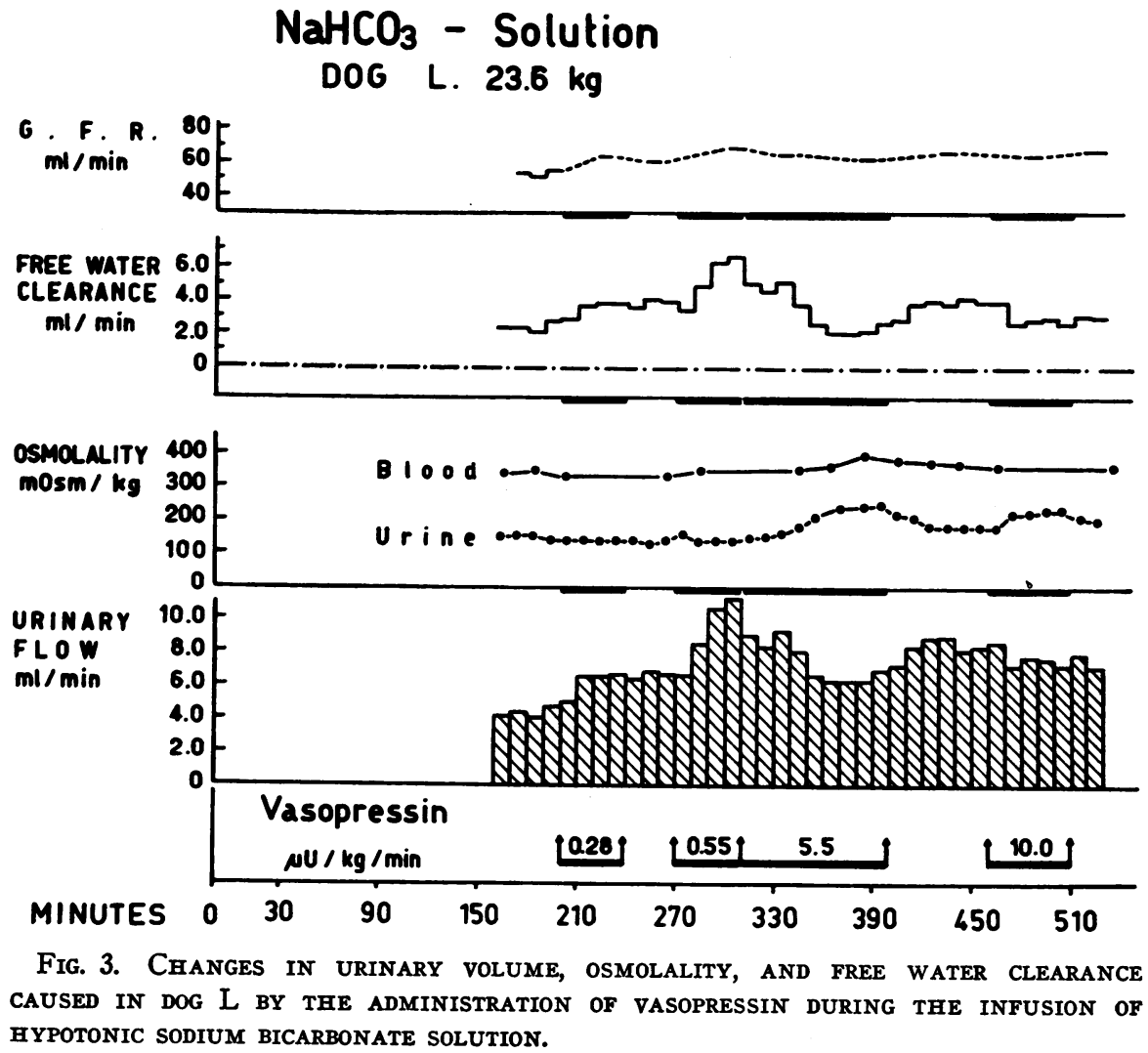

the control periods of the $\mathrm{NaCl}, \mathrm{NH}_{4} \mathrm{Cl}$, and $\mathrm{NaHCO}_{3}$ experiments; the corresponding values for blood $\mathrm{pH}$ ranged between 7.24 to $7.30,7.0$ to 7.18 , and 7.32 to 7.38. During the vasopressin infusion rises in urinary $\mathrm{pH}$ were observed in some of the $\mathrm{NaCl}$ and $\mathrm{NaHCO}_{3}$ experiments, whereas in some of the $\mathrm{NH}_{4} \mathrm{Cl}$ experiments the $\mathrm{pH}$ became somewhat lower. No changes in blood $\mathrm{pH}$ were recorded during the vasopressin administration.

Table V contains data for statistical comparison of the antidiuretic effect of vasopressin during the infusion of the three salt solutions. Although the three groups were compared without subdivision according to vasopressin dosage levels, significant differences became apparent. Urinary flow and free water clearance were significantly more depressed in the $\mathrm{NaCl}$ experiments as compared with $\mathrm{NaHCO}_{3}$, with $\mathrm{p}$ values below 0.01. Still larger differences became apparent between the $\mathrm{NH}_{4} \mathrm{Cl}$ and the $\mathrm{NaHCO}_{3}$ experiments, with $\mathrm{p}<$ 0.001 . The differences between the $\mathrm{NaCl}$ and the $\mathrm{NH}_{4} \mathrm{Cl}$ experiments approached statistical sig- nificance, with $p \backsim 0.06$ for urinary flow and $\mathrm{p}<0.05$ for free water clearance. This comparison between the $\mathrm{NaCl}$ and the $\mathrm{NH}_{4} \mathrm{Cl}$ data is somewhat biased by the fact that the $\mathrm{NaCl}$ series comprises more experiments with larger vasopressin dosages (above $1.5 \mu \mathrm{U}$ per $\mathrm{kg}$ per minute) than the $\mathrm{NH}_{4} \mathrm{Cl}$ series (six in the former as against two in the latter; see Tables II and III). If only the experiments with vasopressin dosage levels up to $1.5 \mu \mathrm{U}$ per $\mathrm{kg}$ per minute were compared, the $p$ values would be below 0.01 also for these two sets of experiments.

\section{Discussion}

The antidiuretic effect of vasopressin differed in magnitude with the three types of salt solutions employed in these experiments. Compared with the sodium chloride experiments, vasopressin had a more pronounced effect in the ammonium chloride experiments and a much less effect in the sodium bicarbonate experiments.

Among the factors affecting urinary flow and 


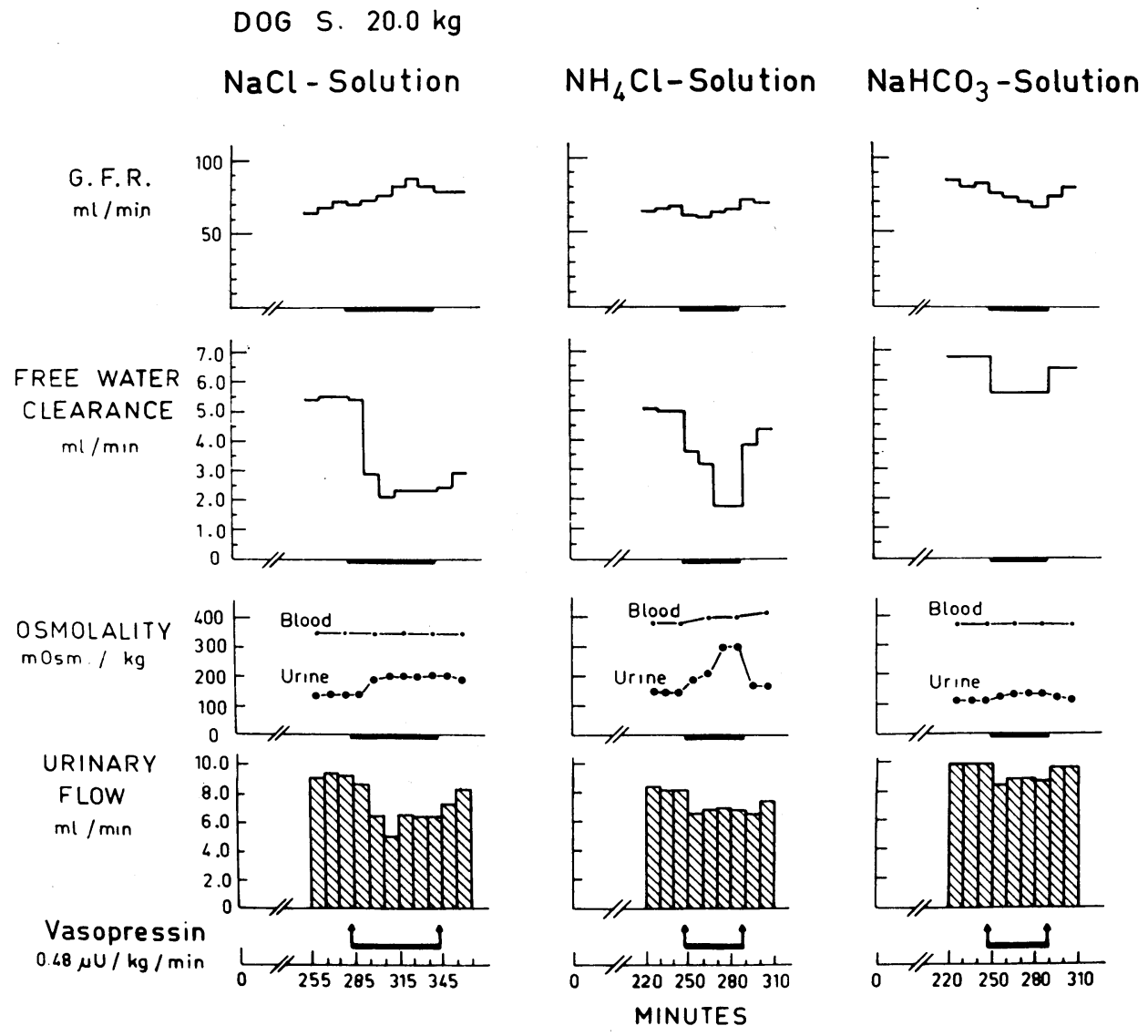

Fig. 4. Changes in urinary volume, osmolality, and Free Water clearance in three SEPARATE EXPERIMENTS ON DOG S WITH THREE DIFFERENT INFUSIONS.

free water clearance, apart from the endogenous and exogenous antidiuretic hormone, changes in the glomerular filtration rate and in total solute excretion need to be considered.

In the majority of instances, changes in urinary flow were accompanied by a steady glomerular filtration rate, whereas in part of the remainder the filtration rate changed in a direction opposite to that of the urinary flow. Moreover, changes in filtration rate in both directions occurred with about equal frequency in the experiments with all three types of salt solutions. The differences in the vasopressin effect observed in these experiments cannot be connected, therefore, with any changes in the glomerular filtration rate.

The effect of solute excretion on the urinary concentration and on the response to vasopressin is of major importance, especially with high rates of solute excretion (12). However, it is safe to assume that at persistently low levels of urinary osmolality during the control periods, an antagonistic effect of the solute excretion on the urinary concentration mechanism can be excluded. Actually, a pronounced antidiuretic response to vasopressin was seen even with high solution excretion rates in all three groups of experiments, whereas, on the other hand, vasopressin failed to reduce urinary flow in some of the sodium bicarbonate experiments even at low rates of solute output. Thus, the differences in the response to vasopressin among the three groups of experiments cannot be related to the magnitude of the solute excretion.

We may conclude, therefore, that the observed differences in the response to vasopressin were caused by the changes in the composition of the body fluids and of the urine, brought about by the different salt solutions. During the infusion 
of an alkaline solution and the secretion of urine with a high $\mathrm{pH}$, a relative vasopressin insensitivity obtained, whereas the infusion of an acid solution, by which the urinary $\mathrm{pH}$ was lowered, enhanced the antidiuretic effect of vasopressin.

It cannot be stated, however, from these experiments, whether the changes in the urine, i.e., the urinary $\mathrm{pH}$ and the excess or relative lack of certain ions, were the deciding factors, or whether the varying response to vasopressin was due to more subtle ionic changes in the plasma or the tubular cells. For the sake of brevity, in the following discussion mainly the changes in $\mathrm{pH}$ will be considered, although other changes on both sides of vasopressin-sensitive membranes may be equally important.

Studies on the transfer of water through the skin of the intact frog and toad and through the isolated toad bladder have shown that in these preparations, too, the effect of vasopressin depends on the ionic composition of the fluid on both sides of the membrane (13-18). The importance of the $\mathrm{pH}$ in particular has been demonstrated by Bentley (14), who found that the permeability of the toad bladder to water, which was increased by Pituitrin, returned to control values when the $\mathrm{pH}$ of the bathing solution on the serosal side was reduced from 7.6 to 6.8 or below. Schwartz and co-workers confirmed this observation (17) and reported also that with constant $\mathrm{pH}$ the vasopressin-induced permeability decreased when the $\mathrm{PCO}_{2}$ on the serosal side was raised (18). Orloff and Handler have made analogous observations on the $\mathrm{pH}$ effect with theophylline, which acts on the toad bladder in a similar way to vasopressin (19).

Although our in vivo experiments can be compared only with caution to these in vitro studies, the following remarks seem appropriate. In the membrane experiments it is the lowering of the $\mathrm{pH}$ at the serosal surface of the bladder or skin that caused a decrease in vasopressin sensitivity, whereas in the experiments described here the rise in $\mathrm{pH}$ at the mucosal surface of the tubular lumen caused a similar response. Thus, the common feature of both types of experiments would be the difference in $\mathrm{pH}$ obtaining across the membranes, a rise in $\mathrm{pH}$ at the outer (epithelial) side causing the same effect as lowering the $\mathrm{pH}$ on the inner (serosal) surface.
TABLE I

Effect of vasopressin in six dogs during the infusions of three different salt solutions; changes in urinary flow, urinary osmolality, and free water clearance

\begin{tabular}{|c|c|c|c|}
\hline & Urinary flow & $\begin{array}{c}\text { Urinary } \\
\text { osmolality }\end{array}$ & $\begin{array}{c}\text { Free water } \\
\text { clearance }\end{array}$ \\
\hline 1. Dog S, 0.48 & $\begin{array}{c}\mathrm{ml} / \min \\
\mathrm{U} / \mathrm{kg} / \mathrm{min}\end{array}$ & $\mathrm{mOsm} / \mathrm{kg}$ & $m l / m i n$ \\
\hline $\begin{array}{l}\mathrm{NaCl} \\
\mathrm{NH}_{4} \mathrm{Cl} \\
\mathrm{NaHCO}_{3}\end{array}$ & $\begin{array}{l}9.1 \rightarrow 5.3 \\
7.3 \rightarrow 6.8 \\
9.8 \rightarrow 8.5\end{array}$ & $\begin{array}{l}140 \rightarrow 200 \\
150 \rightarrow 300 \\
113 \rightarrow 126\end{array}$ & $\begin{array}{l}5.4 \rightarrow 2.3 \\
4.5 \rightarrow 1.8 \\
6.7 \rightarrow 5.5\end{array}$ \\
\hline
\end{tabular}

2. Dog U, $0.48 \mu \mathrm{U} / \mathrm{kg} / \mathrm{min}$

$\begin{array}{llll}\mathrm{NaCl} & 4.0 \rightarrow 4.3 & 161 \rightarrow 168 & 2.2 \rightarrow 2.2\end{array}$

Dog $\mathrm{U}, 0.72 \mu \mathrm{U} / \mathrm{kg} / \mathrm{min}$

$\mathrm{NaCl} \quad 3.8 \rightarrow 3.4 \quad 163 \rightarrow 176 \quad 2.5 \rightarrow 2.0$

$\mathrm{NaHCO}_{3} \quad 3.9 \rightarrow 3.9 \quad 161 \rightarrow 161 \quad 2.4 \rightarrow 2.4$

3. Dog $\mathrm{W}, 0.48 \mu \mathrm{U} / \mathrm{kg} / \mathrm{min}$

$\begin{array}{llll}\mathrm{NaCl} & 4.4 \rightarrow 3.1 & 123 \rightarrow 187 & 3.0 \rightarrow 1.6 \\ \mathrm{NH}_{4} \mathrm{Cl} & 4.4 \rightarrow 1.4 & 133 \rightarrow 304 & 2.7 \rightarrow 0.2 \\ \mathrm{NaHCO}_{3} & 5.1 \rightarrow 4.9 & 113 \rightarrow 163 & 3.6 \rightarrow 2.8\end{array}$

4. $\operatorname{Dog} \mathrm{X}, 0.48 \mu \mathrm{U} / \mathrm{kg} / \mathrm{min}$

$\begin{array}{llll}\mathrm{NaCl} & 6.7 \rightarrow 5.6 & 133 \rightarrow 164 & 3.9 \rightarrow 2.8 \\ \mathrm{NH}_{4} \mathrm{Cl} & 7.3 \rightarrow 1.8 & 133 \rightarrow 426 & 4.3 \rightarrow 0.6 \\ \mathrm{NaHCO}_{3} & 5.8 \rightarrow 5.7 & 183 \rightarrow 186 & 2.4 \rightarrow 2.4\end{array}$

5. $\operatorname{Dog} Y, 0.72 \mu \mathrm{U} / \mathrm{kg} / \mathrm{min}$

$\begin{array}{llll}\mathrm{NaCl} & 6.0 \rightarrow 5.2 & 118 \rightarrow 168 & 3.9 \rightarrow 2.6 \\ \mathrm{NH}_{4} \mathrm{Cl} & 4.1 \rightarrow 2.3 & 109 \rightarrow 455 & 2.9 \rightarrow 3.8 \\ \mathrm{NaHCO}_{3} & 5.5 \rightarrow 5.0 & 133 \rightarrow 150 & 3.1 \rightarrow 2.5\end{array}$

6. $\operatorname{Dog} \mathrm{Z}, 0.72 \mu \mathrm{U} / \mathrm{kg} / \mathrm{min}$

$\begin{array}{llll}\mathrm{NaCl} & 5.0 \rightarrow 4.3 & 130 \rightarrow 155 & 2.9 \rightarrow 2.1 \\ \mathrm{NH}_{4} \mathrm{Cl} & 7.7 \rightarrow 1.5 & 109 \rightarrow 436 & 5.0 \rightarrow 0.5 \\ \mathrm{NaHCO}_{3} & 5.4 \rightarrow 6.7 & 100 \rightarrow 100 & 3.6 \rightarrow 4.5\end{array}$

In human and experimental diabetes insipidus Alexander, Filbin, and Fruchtman (20) were unable to raise the urinary concentration to normal by the administration of vasopressin, and they made the observation that in these experiments the urinary hydrogen concentration was always decreased. In severe human diabetes insipidus we have found that a single injection of 0.02 to $0.03 \mathrm{U}$ of Pitressin during the infusion of sodium bicarbonate solution failed to produce antidiuresis, whereas the same amounts were effective during the infusion of sodium chloride solution (21). Curtis and de Wardener (22) repeated these experiments in two patients with less severe diabetes insipidus. Although these authors obtained antidiuresis during sodium bicarbonate infusions, their figures also show a diminished response to vasopressin during the secretion of alka- 
T. D. ULlMANN, W. J. CZACZKES, AND J. MENCZEL

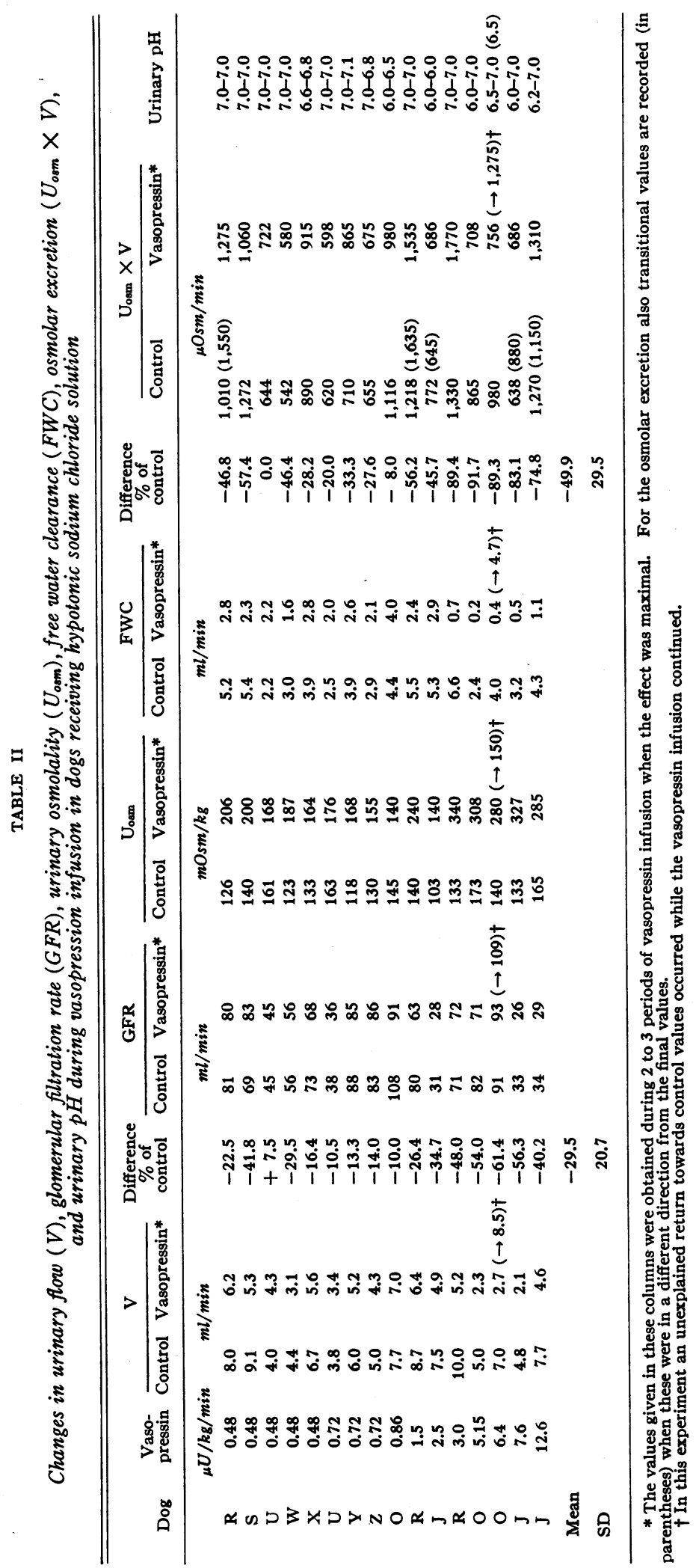




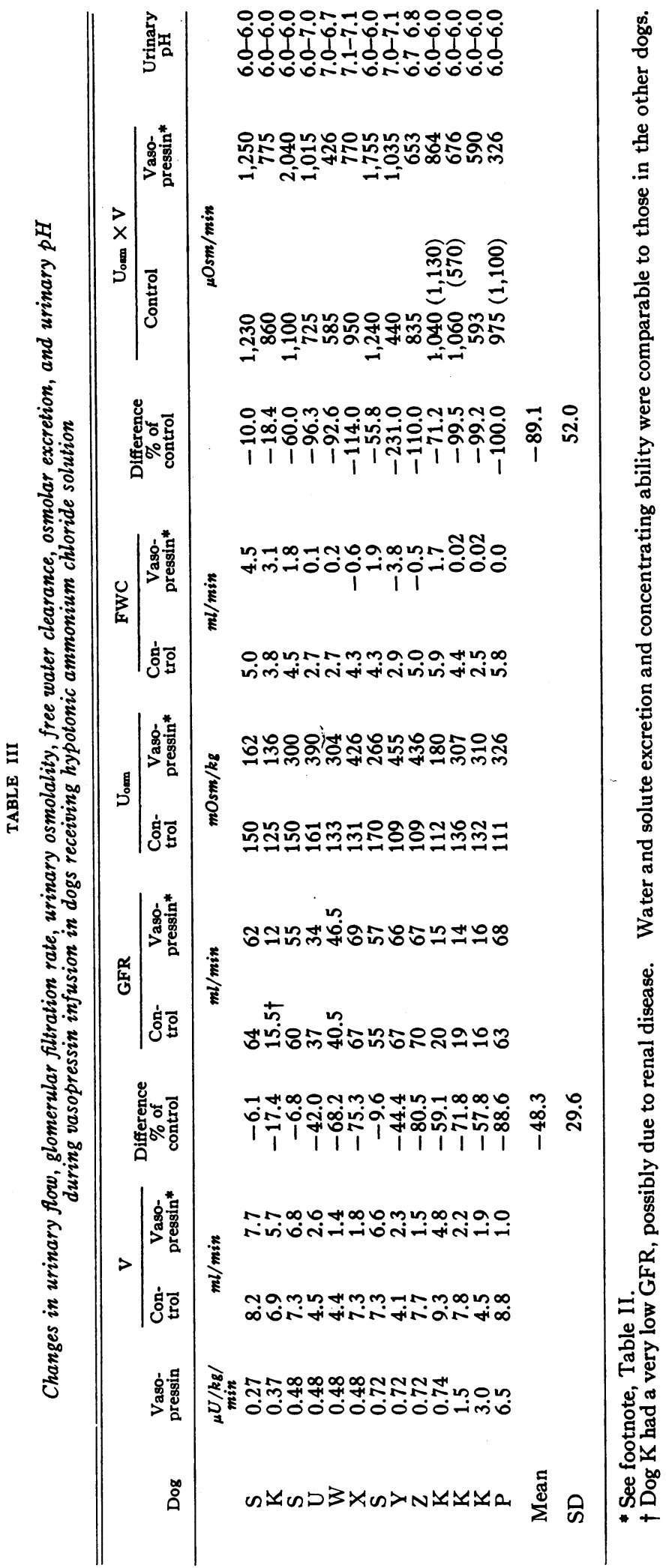


T. D. UllmanN, W. J. CZACZKES, AND J. MENCZEL

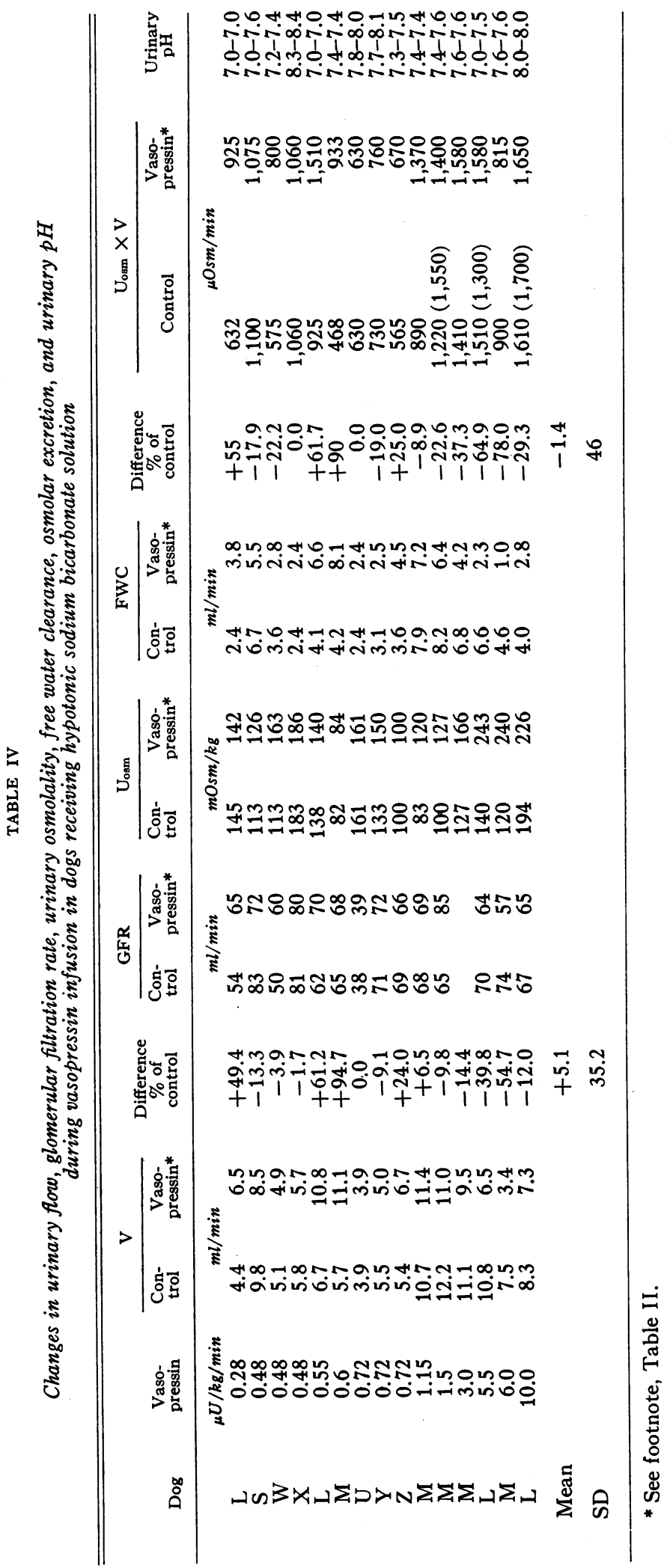


TABLE V

Statistical evaluation of the differences in the effect of vasopressin on urinary flow and free water clearance during the infusion of $\mathrm{NaCl}, \mathrm{NH}_{4} \mathrm{Cl}$, and $\mathrm{NaHCO}_{3}$ solutions

\begin{tabular}{lcccc}
\hline \hline & $\mathrm{D}^{*}$ & $\mathrm{SD} \dagger$ & $t$ & $\mathrm{p}$ \\
\hline $\mathrm{A}$. Urinary flow & & & & \\
$\mathrm{NaCl} / \mathrm{NaHCO}_{3}$ & 34.6 & 10.4 & 3.32 & $<0.01$ \\
$\mathrm{NH}_{4} \mathrm{Cl} / \mathrm{NaHCO}_{3}$ & 53.4 & 12.2 & 4.37 & $<0.001$ \\
$\mathrm{NaCl} / \mathrm{NH}_{4} \mathrm{Cl}$ & 18.8 & 9.71 & 1.93 & $\sim 0.06$ \\
$\mathrm{~B} . \mathrm{Free}$ water clearance & & & \\
$\mathrm{NaCl} / \mathrm{NaHCO}_{3}$ & 46 & 14.0 & 3.2 & $<0.01$ \\
$\mathrm{NH}_{4} \mathrm{Cl} / \mathrm{NaHCO}_{3}$ & 85.7 & 18.6 & 4.6 & $<0.001$ \\
$\mathrm{NaCl} / \mathrm{NH}_{4} \mathrm{Cl}$ & 39.2 & 16.1 & 2.43 & $<0.05$ \\
& & & & \\
\hline
\end{tabular}

* $\mathrm{D}=$ difference between the means of per cent changes obtained from Tables II to IV.

t $\mathrm{SD}=$ standard deviation of the differences of the means.

line urine. In this connection it should be pointed out that the differences in responsiveness to vasopressin, as described in the present experiments and as observed in diabetes insipidus, were only found with small quantities of vasopressin and in the complete or nearly complete absence of endogenous antidiuretic hormone; with larger, albeit still submaximal, doses of vasopressin, the differences tended to disappear. This finding may explain why a dependence of the vasopressin effect on the ionic composition of body fluids and urine has so far escaped attention.

As to the clinical observation of polyuria with alkaline urine, our observations may furnish an explanation for the diminished renal concentration power in some of these conditions. However, the role played in these conditions by the $\mathrm{pH}$ of the urine and by other peculiarities of its ionic structure, or by the composition of the plasma, needs further study.

\section{Summary}

Dogs anesthetized with sodium thiopentone and ethanol were given intravenous infusions of hypotonic solutions of sodium chloride, ammonium chloride, and sodium bicarbonate, at a rate of 7.4 $\mathrm{ml}$ per minute, until a constant flow of hypotonic urine was obtained. Vasopressin was then infused at a constant rate in amounts from 0.27 to 12.6 $\mu \mathrm{U}$ per $\mathrm{kg}$ per minute. Urinary flow, $\mathrm{pH}$, and osmolality and free water clearance and glomerular filtration rate were determined. It was found that during the infusion of sodium chloride, at urinary $\mathrm{pH}$ between 6 and 7, vasopressin caused a reduction in urinary flow and a rise in urinary osmolality, with a fall in free water clearance, even in the smallest amounts given. A still larger antidiuretic effect was obtained with ammonium chloride, at urinary $\mathrm{pH}$ of 5.6 to 7.1. In contrast, during the infusion of sodium bicarbonate, at a urinary $\mathrm{pH}$ of 7.3 to 8.4 , the antidiuretic effect of vasopressin was much less apparent. The differences between either the $\mathrm{NaCl}$ or the $\mathrm{NH}_{4} \mathrm{Cl}$ experiments and those carried out with $\mathrm{NaHCO}_{3}$ were highly significant; those between the $\mathrm{NaCl}$ and the $\mathrm{NH}_{4} \mathrm{Cl}$ experiments approached statistical significance.

The changes in urinary flow and free water clearance were not correlated with changes in glomerular filtration rate and in total solute excretion.

It is concluded from these experiments and from analogous observations in human diabetes insipidus that the antidiuretic effect of vasopressin is modified by the administration of acid and of alkaline salt solutions. During the infusion of alkaline solutions the renal tubules show a decreased responsiveness to exogenous vasopressin, whereas the tubular sensitivity to vasopressin is enhanced during the administration of an acid solution.

\section{Acknowledgment}

We gratefully acknowledge the able technical help given by Mrs. Lisa Ullmann and Mrs. Zwia Bar-Kochba.

\section{References}

1. Cohen, S. I., M. G. Fitzgerald, P. Fourman, W. J. Griffiths, and H. E. de Wardener. Polyuria in hyperparathyroidism. Quart. J. Med. 1957, 26, 423.

2. Fourman, P., B. McConkey, and J. W. G. Smith. Defects of water reabsorption and of hydrogen-ion excretion by the renal tubules in hyperparathyroidism. Lancet 1960, 1, 619.

3. Gill, J. R., Jr., and F. C. Bartter. On the impairment of renal concentrating ability in prolonged hypercalcemia and hypercalciuria in man. J. clin. Invest. 1961, 40, 716.

4. Dustan, H. P., A. C. Corcoran, and I. H. Page. Renal function in primary aldosteronism. J. clin. Invest. 1956, 35, 1357.

5. Ellsworth, R., and W. M. Nicholson. Further ob- 
servations upon the changes in the electrolytes of the urine following the injection of parathyroid extract. J. clin. Invest. 1935, 14, 823.

6. Nordin, B. E. C. The effect of intravenous parathyroid extract on urinary $\mathrm{pH}$, bicarbonate and electrolyte excretion. Clin. Sci. 1960, 19, 311.

7. Manitius, A., H. Levitin, D. Beck, and F. H. Epstein. On the mechanism of impairment of renal concentrating ability in potassium deficiency. J. clin. Invest. 1960, 39, 684 .

8. Manitius, A., H. Levitin, D. Beck, and F. H. Epstein. On the mechanism of impairment of renal concentrating ability in hypercalcemia. J. clin. Invest. 1960, 39, 693.

9. Eggleton, M. G. The diuretic action of alcohol in man. J. Physiol. (Lond.) 1942, 101, 172.

10. Kleeman, C. R., M. E. Rubini, E. Lamdin, and F. H. Epstein. Studies on alcohol diuresis. II. The evaluation of ethyl alcohol as an inhibitor of the neurohypophysis. J. clin. Invest. 1955, 34, 448.

11. Roe, J. H., J. H. Epstein, and N. P. Goldstein. A photometric method for the determination of inulin in plasma and urine. J. biol. Chem. 1949, 178, 839.

12. Lamdin, $E$. Mechanisms of urinary concentration and dilution. Arch. intern. Med. 1959, 103, 644.

13. Bentley, P. J. The effects of vasopressin on water uptake of the toad, Bufo marinus, while bathed in different hypotonic solutions. J. Endocr. 1958, 16, 126.

14. Bentley, P. J. The effects of ionic changes on water transfer across the isolated urinary bladder of the toad Bufo marinus. J. Endocr. 1959, 18, 327.
15. Rasmussen, H., I. L. Schwartz, M. A. Schoessler, and G. Hochster. Studies on the mechanism of action of vasopressin. Proc. nat. Acad. Sci. (Wash.) 1960, 46, 1278.

16. Bentley, P. J. The effects of neurohypophysial extracts on water transfer across the wall of the isolated urinary bladder of the toad Bufo marinus. J. Endocr. 1958, 17, 201.

17. Schwartz, I. L., H. Rasmussen, M. A. Schoessler, L. Silver, and C. T. O. Fong. Relation of chemical attachment to physiological action of vasopressin. Proc. nat. Acad. Sci. (Wash.) 1960, 46, 1288.

18. Holliday, M. A., I. L. Schwartz, J. Marc-Aurele, J. Harrah, and D. Elliott. Effect of $\mathrm{pH}$ and $\mathrm{pCO}_{2}$ on response of the toad bladder to vasopressin. Fed. Proc. 1961, 20, 406.

19. Orloff, J., and J. S. Handler. The similarity of effects of vasopressin, adenosine-3', $5^{\prime}$-phosphate (cyclic AMP) and theophylline on the toad bladder. J. clin. Invest. 1962, 41, 702.

20. Alexander, C. S., D. M. Filbin, and S. A. Fruchtman. Failure of vasopressin to produce normal urine concentration in patients with diabetes insipidus. J. Lab. clin. Med. 1959, 54, 566.

21. Czaczkes, J. W., M. Eliakim, and T. D. Ullmann. Diminished antidiuretic response to Pitressin in diabetes insipidus during the infusion of sodium bicarbonate solution. J. Lab. clin. Med. 1961, 57, 938.

22. Curtis, J. R., and H. E. de Wardener. Effect of urine $\mathrm{pH}$ on the changes in urine concentration produced by vasopressin. Clin. Sci. 1963, 24, 159. 